\title{
Direito Penal Econômico e a Operação Lava-Jato ${ }^{1}$
}

Lino Edmar de Menezes²

\section{RESUMO}

presente artigo analisa os crimes de natureza econômica investigados no âmbito da Operação "Lava-Jato", bem como as suas repercussões na economia de mercado.

Palavras-Chave: Crimes. Econômicos. Investigação. Criminal.

\section{INTRODUÇÃO}

Com a deflagração da "Operação Lava-Jato", em todas as suas fases, evidenciou-se a prática de vários delitos envolvendo empreiteiras, políticos, empregados da Petrobras e também doleiros, estes últimos, como responsáveis pela efetiva garantia do produto da corrupção por meio do crime de lavagem de capitais, providenciando o transporte, ou a entrega direta do dinheiro aos beneficiários, ou, ainda, promovendo as transferências dos numerários para contas situadas no exterior, de modo a dificultar a localização e a origem dos bens, ou valores provenientes da precedente corrupção gerada por uma organização criminosa composta por políticos, empresários e doleiros.

Os repasses dos valores desviados, em geral, tinham por base falsos contratos de prestação de serviços, ou superfaturamento das planilhas de composição de preços dos contratos firmados com a Petrobras. 
Com algumas variantes, em regra, a lavagem era feita pelo método tradicional, de depósitos bancários em contas mantidas em paraísos fiscais e, depois de rastreados, com a colaboração do Ministério Público do país destinatário dos depósitos, especialmente a Suíça, eram identificados os beneficiários dessas propinas e, com base em acordo mútuo de auxílio em matéria penal com esse país, ocorria o imediato bloqueio judicial desses depósitos, para a futura repatriação aos cofres da Petrobras, o que, aliás, já ocorreu em grandes cifras, reembolsadas pela estatal.

Relembre-se que, aos poucos, os investigados resolveram firmar acordos de colaboração premiada com o Ministério Público Federal, facilitando a expansão da operação "Lava-Jato" que, debruçada em documentos e delações sucessivas, já atingiu o próprio Presidente da República, denunciado perante o Supremo Tribunal Federal por corrupção passiva (ainda estão em apuração os crimes de integrar organização criminosa e de obstrução de justiça), sendo que o Conselho Superior do MPF prorrogou a permanência da força-tarefa da Lava-Jato até o final do próximo ano, e a nova Procuradora Geral da República, Raquel Dodge, recentemente nomeada, manifestou seu apoio ao prosseguimento das operações.

A partir das informações colhidas no sítio eletrônico do MPF sobre a operação referida, depreende-se que as várias ações penais já propostas, e muitas já com condenações, enquadraram os autores em alguns crimes tipicamente considerados do âmbito do Direito Penal econômico, tais como: corrupção ativa e passiva; organização criminosa; fraudes em licitações; evasão de divisas; sonegação fiscal; formação de cartel; peculato e o de maior destaque no estudo dos tipos penais econômicos, o crime de lavagem de dinheiro, previsto na Lei n. 9.613/98, alterada pela Lei n. 12.683/2012, que passou a considerar que o produto de qualquer crime antecedente, atendidas as premissas da lei, poderá ser objeto do crime de lavagem de dinheiro.

Deu-se ênfase, nessas divulgações no sítio eletrônico do MPF, 
ao esforço dos integrantes da força-tarefa em repatriar os valores situados no exterior, e as várias condenações a título de multas reparatórias, além da obrigação de os beneficiários das delações devolverem aos cofres da Petrobras as quantias desviadas, computadas pelas empreiteiras na composição dos preços, e nos contratos superfaturados com a estatal, como verba destinada a propinas de altos dirigentes da Petrobras, além de uma conta-corrente mantida pelas empreiteiras para direcionar as propinas aos partidos políticos da base aliada e, também, para benefício direto e pessoal de alguns parlamentares.

No presente artigo, pretende-se pôr em relevo a incidência dos crimes econômicos revelados nessas operações, bem como alguns aspectos doutrinários relevantes sobre esse ramo do direito criminal que, embora não seja autônomo, merecem ser destacados alguns conceitos e categorias próprias dessa faceta do direito penal que já goza de relativa autonomia, inclusive compondo a grade curricular de alguns cursos de graduação em Direito.

\section{A NATUREZA DOS CRIMES ECONÔMICOS}

A doutrina procura oferecer um conceito para o direito penal econômico, merecendo transcrever a lição do Professor Manuel Pedro Pimentel (1973), externando que esse ramo do direito compreende:

Um sistema de normas que defende a política econômica do Estado, permitindo que esta encontre os meios para a sua realização. São, portanto, a segurança e a regularidade da realização dessa política que consiste precipuamente o objeto do direito penal econômico. Além do patrimônio de indefinido número de pessoas, são também objeto da proteção legal o patrimônio público, o comércio em geral, a troca de moedas, a fé pública, e a Administração Pública, em certo sentido. (PIMENTEL, 1973, p.21).

No mesmo sentido é a opinião de William Terra de Oliveira, sin- 
tetizando que:

Os traços distintivos dessa espécie de criminalidade residem nos fatos de tutelarem bens jurídicos supraindividuais, relacionados à preservação dos valores da ordem econômica, de envolverem em seu polo ativo, pessoas de elevado estatuto social, e de serem um meio para a realização dos objetivos delineados pelo chamado Estado democrático e social de Direito. (OLIVEIRA, p.235).

Os doutrinadores relacionam alguns delitos com feições do direito penal econômico, a partir do bem jurídico protegido, reconhecendo, outrossim, que, em regra, os conceitos e categorias do direito penal em sua parte geral aplicam-se a essas espécies de delitos.

Normalmente, os estudiosos relacionam os seguintes delitos como da seara do direito penal econômico, tendo em conta o bem jurídico que pertine com a proteção das relações econômicas, empresariais e consumeristas, bem como quando afetam a moralidade administrativa, envolvendo, portanto, direitos transindividuais ${ }^{3}$ :

\begin{tabular}{|c|c|c|}
\hline NORMA & $\begin{array}{l}\text { OBJETIVIDADE } \\
\text { JURÍDICA }\end{array}$ & $\begin{array}{c}\text { BEM } \\
\text { JURÍDICO }\end{array}$ \\
\hline $\begin{array}{l}\text { Lei n. } 8.137 / 90 \\
\quad\left(\text { art. } 1^{\circ} \text { a } 3^{\circ}\right)\end{array}$ & $\begin{array}{c}\text { Delitos contra a ordem } \\
\text { tributária }\end{array}$ & $\begin{array}{c}\text { Erário público e proteção } \\
\text { da política socioeconômica } \\
\text { do Estado }\end{array}$ \\
\hline Lei n. $8.137 / 90\left(\right.$ art. $4^{\circ}$ a $\left.6^{\circ}\right)$ & $\begin{array}{l}\text { Delitos contra a ordem } \\
\text { econômica }\end{array}$ & $\begin{array}{l}\text { Livre concorrência e } \\
\text { livre iniciativa }\end{array}$ \\
\hline Lei n. 8.137/90 (art. $\left.7^{\circ}\right)$ & $\begin{array}{l}\text { Delitos contra as } \\
\text { relações de consumo }\end{array}$ & $\begin{array}{l}\text { Interesses econômicos ou } \\
\text { sociais do consumidor }\end{array}$ \\
\hline Lei n. 8.176/91 & $\begin{array}{l}\text { Delito contra a ordem } \\
\text { econômica }\end{array}$ & Fontes energéticas \\
\hline Lei n. 8.078/90 & $\begin{array}{c}\text { Delitos contra as relações } \\
\text { de consumo }\end{array}$ & $\begin{array}{l}\text { Relações jurídicas } \\
\text { de consumo }\end{array}$ \\
\hline Lei n. $7.492 / 86$ & $\begin{array}{l}\text { Delitos contra o sistema } \\
\text { financeiro nacional }\end{array}$ & $\begin{array}{l}\text { Higidez da gestão das } \\
\text { instituições financeiras }\end{array}$ \\
\hline $\begin{array}{c}\text { Lei n. 9.613/98 (modificada pela } \\
\text { Lei n. } 12.683 / 2012)\end{array}$ & $\begin{array}{l}\text { Delitos de ocultação de bens } \\
\text { ou lavagem de capitais }\end{array}$ & $\begin{array}{c}\text { Administração da Justiça e a } \\
\text { ordem socioeconômica }\end{array}$ \\
\hline $\begin{array}{l}\text { Código Penal (Art. } \\
\text { 168-A e 337-A) }\end{array}$ & $\begin{array}{l}\text { Delitos contra o sistema } \\
\text { previdenciário }\end{array}$ & $\begin{array}{l}\text { Interesse patrimonial da } \\
\text { previdência social }\end{array}$ \\
\hline
\end{tabular}

3 Cf.: http://www.stf.jus.br/repositorio/cms/portal/tvjustica 


\begin{tabular}{|c|c|c|}
\hline Código Penal (Art. 334) & $\begin{array}{c}\text { Delitos de contrabando e } \\
\text { descaminho }\end{array}$ & $\begin{array}{c}\text { Interesse econômico do Esta- } \\
\text { do; proteção do mercado }\end{array}$ \\
\hline $\begin{array}{c}\text { Código Penal (Art. 359-A a } \\
\text { 359-H) }\end{array}$ & $\begin{array}{c}\text { Delitos contra as } \\
\text { finanças públicas }\end{array}$ & $\begin{array}{c}\text { Regularidade das } \\
\text { finanças públicas }\end{array}$ \\
\hline $\begin{array}{c}\text { Código Penal } \\
\text { (Art. 317 e 333) }\end{array}$ & $\begin{array}{c}\text { Delitos contra a } \\
\text { Administração Pública }\end{array}$ & $\begin{array}{c}\text { Regularidade e moralidade } \\
\text { das funções estatais }\end{array}$ \\
\hline
\end{tabular}

Esses delitos se destacam pelo bem jurídico protegido, além do que, em regra, são considerados crimes de perigo abstrato, pois a conduta (ação ou omissão) prevista na moldura típica, traz a presunção de que é lesiva ao mundo econômico, não se exigindo, de forma individual e concreta, uma lesão a uma vítima determinada, eis que, por definição, são crimes de natureza transindividuais ou difusos.

Calha observar que os crimes investigados no âmbito da Lava-Jato são todos dessa natureza, pois afetam bens jurídicos transindividuais, sendo o mais grave deles a lavagem de dinheiro, que representa um verdadeiro exaurimento da ofensa ao meio econômico, com a inserção na cadeia produtiva, comercial e de serviços, do dinheiro sujo proveniente dos crimes antecedentes, o que é presumido afetar o equilíbrio do mercado, das relações econômicas e da livre concorrência. Até mesmo o crime de sonegação fiscal praticado por uma empresa tem sérias consequências no mundo econômico, conforme alerta a professora Ela Wiecko. (CASTILHO, 2007).

\section{OS EFEITOS DA OPERAÇÃO LAVA-JATO NA ECONOMIA}

Apesar dos esforços para se combater esses delitos da alta criminalidade - também chamados de colarinho branco - alguns setores da imprensa nacional chegaram a criticar os efeitos danosos da "Operação Lava-Jato" no desenvolvimento do País, como foi o caso da reportagem da revista Carta Capital, com o título "A Lava-Jato e o Governo destroem a economia", tecendo considerações de conteúdo econômico para descredenciar as ações do Ministério Público e do Judiciário, principalmente o fato de não se exigir desses funcionários 
"nenhuma experiência anterior em negócios e economia", destacando que:

O Brasil pagará por gerações pelos erros cometidos. A lava-jato se gaba de ter devolvido ao País 2 bilhões de reais. E quantos bilhões a gente gastou para isso? Do ponto de vista econômico, essa conta não fecha. A maioria das consultorias, que calcularam o prejuízo provocado à economia pela operação estimou-o em cerca de 120 bilhões de reais. (DRUMMOND, 2016).

No referido artigo, a crítica continua, profetizando:

O dano deve aumentar. Cerca de 31 bilhões de reais em projetos aprovados de aeroportos, rodovias e mobilidade urbana, com capacidade de gerar 900 mil empregos, segundo o cálculo dessa revista, estão parados, porque o financiamento com o BNDES, contratado com os vencedores das licitações, todos envolvidos na lava jato, não sai.

E, concluindo, prevê a quebradeira das empreiteiras envolvidas na lava-jato:

Na terça-feira 11, o BNDES anunciou a suspensão de pagamentos e a revisão de 47 contratos de exportação de serviços de engenharia de empreiteiras implicadas na operação, no valor de 13,5 bilhões de reais. Receia-se no setor que, por meio de relicitações, as empreiteiras nacionais serão afastadas em definitivo dos financiamentos de longo prazo do banco, imprescindíveis às grandes obras públicas, e substituídas por construtoras estrangeiras.

A troca talvez não seja tão fácil quanto alguns presumem. Empresas estrangeiras não virão ao Brasil de uma hora para outra antes de saber como fica a segurança jurídica e sob que condições vão trabalhar. Nós podemos permanecer cinco ou dez anos sem ter quem faça a nossa infraestrutura. Como é que fica?

Em sentido contrário, apoiando as ações da "Lava-Jato", temos vários outros articulistas enfatizando o inadiável combate à corrupção 
como forma de termos instituições democráticas mais acreditadas e eficientes, além de evitar a deletéria influência de recursos escusos na economia, geradores de um clima econômico de investimentos duvidosos e de abalos no mercado, ante o fenômeno da concorrência desleal em vários setores da economia nacional.

Essa posição foi manifestada em artigo publicado na internet, no sítio eletrônico "Brasil-economia e Governo", com as seguintes palavras de apoio do Instituto Braudel, 2015:

A lava-jato deve ser vista como a afirmação de princípios fundamentais de uma sociedade saudável: a lei vale para todos; a corrupção não deve ser tolerada; o crime deve ser punido. Condená-la em função dos efeitos colaterais que provoca, equivale a dizer que um paciente com câncer não deve se submeter à quimioterapia para não sofrer enjoo ou correr o risco de infecções oportunistas. Por pior que sejam esses efeitos, não há saída sem a quimioterapia.

O risco que a Lava-Jato encerra não é a perda de pontos percentuais do PIB. O risco real é o nosso sistema democrático não aguentar o impacto das revelações. A descrença nos três Poderes e nos partidos políticos pode abrir espaço para 'salvadores da pátria, que surgiriam como infecções oportunistas ao longo do tratamento e que poderiam levar a resultados tão ruins quanto o próprio câncer.

Com o intuito de passar o País a limpo, alguns novos personagens, não identificados como políticos tradicionais, podem se eleger com proposta que suprimam o funcionamento das instituições democráticas. O País já se viu esse filme e sabemos que tal opção não é promissora.

O desafio é nos mantermos nos trilhos da legalidade e aguentar o tranco até o final das investigações. Precisamos também aproveitar a comoção nacional e a fragilidade dos grupos que patrocinam interesses escusos para aprovar reformas importantes, que melhorem a qualidade das nossas instituições. Poderíamos começar com uma nova rodada de privatizações, que retirassem decisões empresariais da órbita de interesses políticos, bem como fazer melhorias nas regras de governança das empresas estatais e dos fundos de pensão, dois focos de má gestão e corrupção, assim como reduzir a influência política sobre as agências reguladoras. Importante também seria aumentar a probabilidade de punição e o tamanho da pena e da expropriação de recursos dos condenados por corrupção. 
Convém ressaltar que, no plano institucional, as críticas à "Lava-Jato" já foram repudiadas pelo atual Procurador Geral da República, que, em entrevistas à imprensa e também em encontros com empresários, tranquilizou a todos sobre os supostos e alegados efeitos negativos da operação na economia. A posição do Procurador Geral foi fielmente reproduzida em artigo virtual da Folha de São Paulo, de 17 de janeiro de 2017, abaixo transcrito:

O procurador-geral Rodrigo Janot dirá nesta quarta-feira (18), para uma plateia essencialmente de empresários, que a Operação Lava-Jato, que ele comanda e já mandou para a cadeia um punhado de executivos de grosso calibre, não é um ataque ao capitalismo.

Ao contrário, dirá Janot, trata-se de defender a economia de mercado, porque tolerar a corrupção praticada por empresas leva inexoravelmente a um capitalismo de compadrio. Esse tipo de capitalismo resulta inexoravelmente em distorções na competição - regra de ouro do capitalismo - porque os compadres dos governantes de turno têm preferências nas obras públicas, em troca de propinas ${ }^{4}$.

\section{CONCLUSÃO}

Convém esclarecer ao grande público que a repressão aos crimes por parte dos órgãos estatais independe das opiniões dos analistas econômicos, políticos, empresariais ou dos meios de comunicação.

Prevalece no País o princípio da obrigatoriedade da persecução penal nos crimes de ação penal pública incondicionada, como são todos aqueles investigados durante a Operação Lava-Jato, e, para além disso, o Brasil firmou inúmeros tratados internacionais para combater a macrocriminalidade, obrigando-se a punir os autores de crimes considerados transnacionais, pondo em relevo as ações das organizações criminosas que, por meio de numerosos delitos graves, injetam recursos ilícitos na economia dos países de todo o

4 Cf. em: http://www.folha.uol.com.br/poder/2017/01/1850560-lava-jato-e-pro-mercado-diz-janot-em-davos.shtml 
planeta, não se justificando que o Estado escamoteie a apuração dessas condutas criminosas sob os falsos argumentos de influência deletéria no meio econômico.

Aliás, os próprios tratados internacionais preveem sanções para quando o País subscritor deixar de adotar as medidas previstas nos referidos tratados, sendo certo que essas convenções internacionais procuram universalizar a punição dos criminosos, dentro de uma concepção de um direito penal internacional, em razão da conhecida cláusula dos tratados que obriga o País-parte a "extraditar ou processar" os autores de crimes que residam em seu território, sendo uma manifestação da chamada "Justiça penal cosmopolita", desejada por todos nós.

\section{CRIMINAL ECONOMIC LAW AND PERATION CAR WASH}

\section{ABSTRACT}

This article analyzes the economic crimes investigated in the framework of operation "car wash", as well as its impact on market economy.

Keywords: Crimes. Economics. Investigation. Criminal.

\section{REFERÊNCIAS}

A lava Jato e o governo destroem a economia. Carta Capital, política por Carlos Drummond, 31/10/2016. In: << https://www.cartacapital.com.br/ revista/923/a-lava-jato-e-o-governo-destroem-a-economia >>.

BRASIL-Economia e Governo. publicação do Instituto Braudel, ano 2015. CASTILHO, Ela Wiecko. Crimes antecedentes e lavagem de dinheiro. Revista Brasileira de Ciências Criminais. São Paulo, v. 197, ano 2007.

NUCCI, Guilherme de Souza. Manual de Direito Penal. Rio de Janeiro: Editora Forense, 2016. 
OLIVEIRA, William Terra. Questões em torno do novo Direito Penal Econômico. Revista Brasileira de Ciências Criminais. RT, ano 3, n. 11, p. 235. Operação Lava Jato é pró-mercado, diz Janot em Davos. In: <<http://www. folha.uol.com.br/poder/2017/01/1850560-lava-jato-e-pro-mercado-dizjanot-em-davos.shtml >>.

PIMENTEL, Manoel Pedro. Direito Penal Econômico. São Paulo: Revista dos Tribunais, 1973, p. 21.

Supremo Tribunal Federal. In: <<http://www.stf.jus.br/repositorio/cms/ portal/tvjustica >> 